\title{
PERSONALIZING CLASSROOM INSTRUCTION \\ TO ACCOUNT FOR MOTIVATIONAL AND DEVELOPMENTAL DIFFERENCES
}

\author{
Linda Taylor \\ Los Angeles Unified School District \\ University of California, Los A ngeles, California, USA \\ Howard S. Adelman \\ University of California, Los A ngeles, California, USA
}

\begin{abstract}
A $n$ orientation to teaching is outlined that stresses the necessity of matching both motivation and capabilities. This model encompasses both regular instruction and remediation. The approach begins with an emphasis on improving regular instruction by enhancing the ability of teachers to personalize instruction. For students found to need additional assistance, remediation is introduced and pursued using a hierarchical framework. The emphasis at all times $i s$ on use of the least intervention needed and maintaining a focus on motivation as a primary consideration.
\end{abstract}

A transactional perspective of human behavior (see discussion by Bandura, 1978) recognizes that preventing and remedying many learning problems require the involvement of all teachers in comprehensive eff orts to address the wide range of barriers that interfere with classroom learning and teaching (Adelman \& Taylor, 1993, 1994, 1997). This includes making significant changes in learning environments and instructional systems to enhance literacy. In the vernacular of teaching, a transactional perspective states that such modifications should be designed to meet learners where they are. In practice, this old adage is usually interpreted as a call for matching a student's current capabilities (e.g., knowledge and skills). However, matching motivation also is essential. Such a motivational emphasis encompasses concerns about intrinsic motivation and overcoming avoidance motivation (Deci \& Chandler, 1986).

This article was prepared in conjunction with work done by the Center for Mental Health in Schools at UCLA, which is partially supported by funds from the U.S. Department of Health and Human Services, Public Health Services, Health Resources and Services Administration, Bureau of Maternal and Child Health, Office of Adolescent Health.

Address correspondence to Howard Adelman, Department of Psychology, UCLA, Box 95163, Los Angeles, CA 90095-1563, USA. 


\begin{tabular}{|c|c|c|}
\hline $\begin{array}{c}\text { Regular programs } \\
\text { (nonpersonalized) }\end{array}$ & $\begin{array}{c}\text { Modify progmams } \\
\text { If it is not feasible to change a particular } \\
\text { teacher's program, move students who } \\
\text { manifest problems learning out } \\
\text { of that classroom }\end{array}$ & $\begin{array}{c}\text { Personalized programs } \\
\text { Step 1. Personalizing the } \\
\text { environment and program }\end{array}$ \\
$\begin{array}{c}\text { (Step 2 is added only for } \\
\text { students who continue to } \\
\text { have problems) }\end{array}$ \\
\hdashline$-\begin{array}{c}\text { Step 2. Remediation* } \\
\text { (maintained only as long as } \\
\text { needed* - see below) }\end{array}$ \\
\hline
\end{tabular}

*At Step 2, the course of remediation differs for minor and severe problems

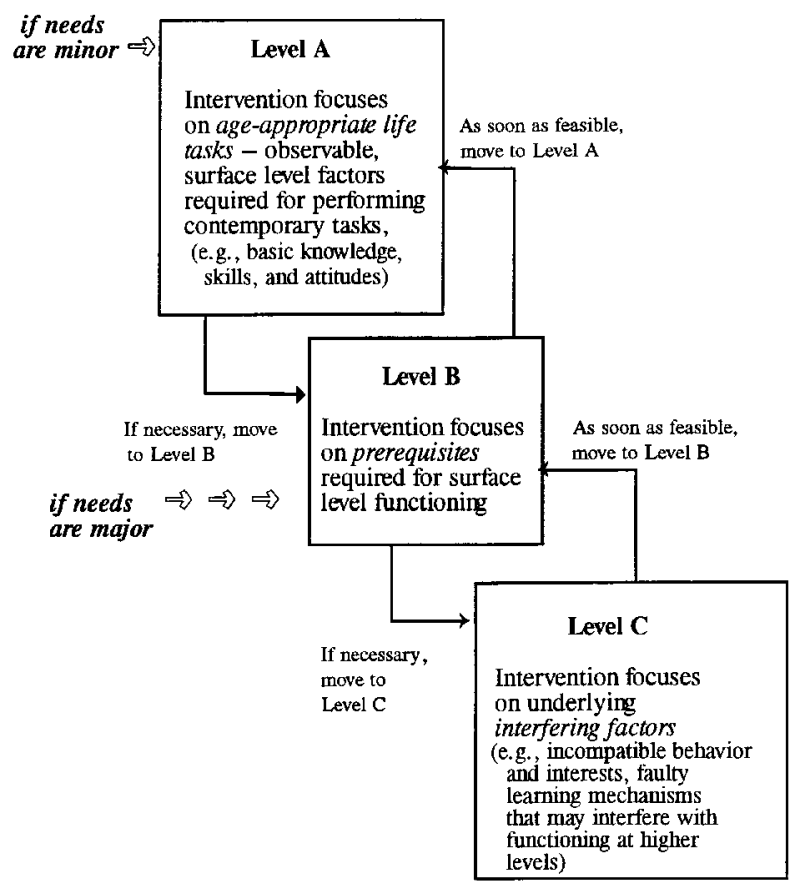

Adapted from: H.S. Adelman \& L. Taylor (1993). Leaming problems and leaming disabilities; Moving forward. Pacific Grove, CA: Brooks/Cole.

FIGURE 1 Sequences and levels in providing a good match and determining least intervention needed.

It is clear that the emphasis on matching capabilities is the prevalent orientation in the literature on teaching reading and writing (Jordan \& Goldsmith-Phillips, 1994; Joyce \& Weil, 1996; Lyon \& Moats, 1997; Reid \& Maag, 1998). Motivational considerations are 
often given short shrift. The irony, of course, is that most teachers recognize that motivational factors often play a key role in accounting for poor instructional outcomes. One of the most common laments among teachers is: "They could do it, if only they wanted to!" Teachers also know that good reading abilities are more likely to emerge when youngsters are motivated not only to pursue class assignments, but also are interested in reading as a recreational activity.

Our intent here is to outline an orientation to teaching that stresses the necessity of matching both motivation and capabilities and a model that encompasses both regular instruction and remediation. The approach outlined begins with an emphasis on improving regular instruction by enhancing the ability of teachers to personalize instruction. For students found to need additional assistance, remediation is introduced (see Figure 1).

At first glance, it may seem inconsistent that we would stress a transactional perspective of learning and instruction and also advocate sequential and somewhat hierarchical approach to intervention for youngsters experiencing difficulty. Our work reflects both an appreciation that learning and teaching are dynamic and nonlinear processes and that some learners experience problems that require the use of something more than the best that individualized or even personalized instruction offers. We continue to refer to that something more as remediation, although we would welcome someone inventing a better term. Among those who focus on remediation, there continues to be debate over whether to focus on observable skills or possible underlying problems (see Adelman \& Taylor, 1993, 1994). Our approach to remediation is an attempt to deal with this matter in an empirical way. Before discussing the model in greater detail, it will help if we expand briefly on our view of the concepts of the match and personalized instruction.

\section{PERSONALIZATION AND MATCHING MOTIVATION AND CAPABILITY}

The theoretical concept of the match (as advocated throughout the body of work produced by leading scholars such as Bruner, 1966; Hunt, 1961; Piaget, 1952; Vygotsky, Vygotsky, \& John-Steiner, 1980) reflects a transactional view of learning and learning problems. In the more recent literature, the tendency is to refer to the concept of the match as the problem of fit. In practice, all individualized and personalized interventions are based on this concept. The major 
thrust in most individualized approaches is to account for individual diff erences in capability, whereas personalization has been defined as accounting for individual differences in both capability and motivation (Adelman \& Taylor, 1993, 1994).

Personalization represents an application of the principles of normalization and least intervention needed (which encompasses the concept of least restrictive environment). Personalization can be treated as a psychological construct by viewing the learner's perception as a critical factor in defining whether the environment appropriately accounts for the learner's interests and abilities (Adelman \& Taylor, 1993). In defining personalization as a psychological construct, learners' perceptions of how well teaching and learning environments match their interests and abilities become a basic assessment concern.

Properly designed and carried out, personalized programs should reduce the need for remediation related to reading and writing. That is, maximizing motivation and matching developmental capability should be a sufficient condition for learning among those students whose difficulties are not the result of interfering internal factors. Personalized programs also represent the type of program regular classrooms might implement in order to significantly improve the efficacy of inclusion, mainstreaming, and prereferral interventions.

As we have indicated, most teachers recognize the importance of designing interventions to be a good fit with the current capabilities of their students. Often, however, the same degree of emphasis is not given in schools to individual differences in motivation. This is not to say that the matter has been ignored in the literature on motivation (Deci \& Ryan, 1985; Dev, 1997; Stipeck, 1998; Weiner, 1985). The value of attending to motivational considerations related to literacy in general and reading in particular is a major theme in products from those associated with the National Reading Research Center (e.g., Guthrie \& Wigfield, 1997; Morrow \& Sharkey, 1993; Sweet \& Guthrie, 1996).

From a cognitive-affective theoretical viewpoint, there are very good reasons for teachers to make motivation a primary consideration. For one thing, motivation is a key antecedent condition. That is, it is a prerequisite to student performance. Poor motivational readiness may be a cause of poor learning and a factor maintaining learning problems. Thus, strategies are called for that can result in a high level of motivational readiness (including reduction of avoidance motivation)-so that students are mobilized to participate.

Motivation is also a key ongoing process concern. Processes must 
elicit, enhance, and maintain motivation so that students stay mobilized. For example, an individual may value learning to read but may not be motivated to pursue the processes used to teach reading. Many students are motivated when they first encounter reading instruction but do not maintain that motivation.

When they arise, negative motivation and avoidance reactionsand the conditions likely to generate them-must be circumvented or at least minimized. Of particular concern are activities people perceive as unchallenging, uninteresting, overdemanding, or overwhelming. Students react against structures that seriously limit their range of options or are overcontrolling and coercive. Examples of conditions that can have a negative impact on a person's motivation are sparse resources, excessive rules, and a restrictive day-in, day-out emphasis on drill and remediation.

Finally, enhancing intrinsic motivation is a basic outcome concern. Although a student may function well-enough to learn the basics of reading and writing at school, the youngster may have little or no interest in using newly acquired knowledge and skills unless a situation demands it. Responding to this concern requires strategies to enhance stable, positive, intrinsic attitudes that mobilize an individual's ongoing pursuit of desired ends in nondemand situations. Such intrinsic attitudes are needed to generate the type of motivated practice (for example, reading for pleasure) that is essential if what has just been learned is to be mastered and assimilated.

No teacher has control over all the important elements involved in learning. Indeed, teachers actually can affect only a relatively small segment of the physical environment and social context in which learning is to occur. Because this is so, it is essential that teachers begin with an appreciation of what is likely to affect a student's positive and negative motivation to learn. For example, our work (as synthesized in Adelman \& Taylor, 1993, 1994) suggests teachers need to pay particular attention to the following points:

- Optimal performance and learning require motivational readiness. Readiness is no longer viewed in the old sense of waiting until an individual is interested. Rather, it is understood in the contemporary sense of offering stimulating environments that can be perceived as vivid, valued, and attainable.

- Teachers not only need to try to increase motivation-especially intrinsic motivation-but also to avoid practices that decrease it. For example, under some circumstances, overreliance on extrinsics to entice and reward may decrease intrinsic motivation. 
- Motivation represents both a process and an outcome concern. For example, programs must be designed to maintain, enhance, and expand intrinsic motivation for pursuing current learning activities and also for involvement in related learning activities beyond the immediate lesson and outside of school.

- Increasing motivation requires focusing on a student's thoughts, feelings, and decisions. In general, the intent is to use procedures that can reduce negative and increase positive feelings, thoughts, and coping strategies. With learning problems, it is especially important to identify and minimize experiences that maintain or may increase avoidance motivation.

The point about minimizing experiences that have negative associations deserves special emphasis. Students with learning problems may have developed extremely negative perceptions of teachers and programs. In such cases, they are not likely to be open to people and activities that look like the same old thing. Major changes in approach are required for the student to notice that something has changed. Exceptional efforts must be made to have these students view the teacher as supportive (rather than controlling or indiff erent) and perceive content, outcomes, and activity options as personally valuable and obtainable.

Major intervention implications are that a program must provide for a broad range of content, outcomes, and procedural options, including a personalized structure to facilitate learning, and then provide opportunities for learner decision making. There also must be nonthreatening ways to provide ongoing information about learning and performance. Such procedures are fundamental to mobilizing most learners in classroom programs and can be essential for those experiencing learning difficulties.

For learners who are motivated, facilitating learning involves maintaining and possibly enhancing motivation and helping establish ways for learners to attain their goals. The intent is to help the individual learn eff ectively, efficiently, and with a minimum of negative side eff ects. Sometimes, all that is needed is to help clear the external hurdles to learning. At other times, facilitating learning requires leading, guiding, stimulating, clarifying, and supporting. Although the process involves knowing when, how, and what to teach, it also involves knowing when and how to structure the situation so that people can learn on their own (Fuchs, Fuchs, Mathes, \& Simmons, 1997; Johnson \& Pugach, 1991; Marr, 1997; Slavin, 1994; Slavin, Karweit, \& Madden, 1989). 


\section{A SEQUENTIAL AND HIERARCHICAL MODEL FOR CLASSROOM INSTRUCTION}

Based on the above thinking, we use a two-step approach for revamping classrooms to better address the needs of all learners (Adelman, 1971; Adelman \& Taylor, 1977, 1993, 1994). As illustrated in Figure 1, the first step is personalization of the classroom program. After a personalized program is properly implemented, it is to be expected that, though mobilized to try harder, some students will continue to have significant learning problems (e.g., those whose difficulties are the result of interfering internal factors). In effect, personalization amounts to appropriate accommodation of individual diff erences in motivation and capability. It is an essential first step in assessing who does and does not require remedial interventions.

Depending on problem severity and pervasiveness, remediation involves one (or more) of three levels of focus. Level A pursues observable problems related to age-appropriate life tasks (basic knowledge, skills, and interests) level $\mathrm{B}$ focuses on missing prerequisites for learning and level $\mathrm{C}$ looks for underlying problems interfering with learning (disabilities, avoidance motivation, serious interfering behaviors sometimes related to emotional disorders).

In personalizing teaching, decisions about general curriculum goals for a student are based on assessment of the individual's interests and abilities. The level of remediation on which to focus with respect to any curricular goal is determined by assessing an individual's responses to daily instruction. Specific remedial objectives are formulated initially through dialogue with the learner to generate processes and outcomes that are valued and perceived as attainable. General goals and specific objectives are modified through ongoing dialogues informed by analyses of task performance and supplemented with formal assessment devices when necessary.

Procedures used for personalization and remediation must reflect a primary, systematic focus on motivation. In particular, they should emphasize (a) assessing motivation, (b) overcoming negative attitudes, (c) enhancing motivational readiness for learning, (d) maintaining intrinsic motivation throughout the learning process, and (e) nurturing the type of continuing motivation that results in the learner engaging in activities away from the teaching situation. Attending to these matters is seen as essential to maximizing maintenance, generalization, and expansion of learning. Failure to attend systematically and comprehensively to these matters means approaching passive (and often hostile) learners with methods that confound diagnostic and research efforts and may just as readily 
exacerbate as correct learning and behavior problems (Adelman \& Taylor, 1990; Brehm \& Brehm, 1981; Deci \& Ryan, 1985; Jordan \& Goldsmith-Phillips, 1994).

\section{Step 1 : Personalized Instruction}

Table 1 outlines the underlying assumptions and major program elements of personalized programs. As defined above, personalization stresses the importance of a learner's perception of how well the

TABLE 1 Underlying Assumptions and Major Program Elements of a Personalized Program

I. Underlying Assumptions

The following are basic assumptions underlying personalized programs as we conceive them.

- Learning is a function of the ongoing transactions between the learner and the learning environment (with all it encompasses).

- Optimal learning is a function of an optimal match between the learner's accumulated capacities, attitudes, and current state of being and the program's processes and context.

- Matching both a learner's motivation and pattern of acquired capacities must be primary procedural objectives.

- The learner's perception is the critical criterion for evaluating whether a good match exists between the learner and the learning environment.

- The wider the range of options that can be offered and the more the learner is made aware of the options and has a choice about which to pursue, the greater the likelihood that he or she will perceive the match as a good one.

- Besides improved learning, personalized programs enhance intrinsic valuing of learning and a sense of personal responsibility for learning. Furthermore, such programs increase acceptance and even appreciation of individual differences, as well as independent and cooperative functioning and problem solving.

II. Program elements

Major elements of personalized programs as we have identified them are:

- Regular use of informal and formal conferences for discussing options, making decisions, exploring learner perceptions, and mutually evaluating progress;

- A broad range of options from which the learner can make choices with regard to types of learning content, activities, and desired outcomes;

- A broad range of options from which the learner can make choices with regard to facilitation (support, guidance) of decision making and learning;

- Active decision making by the learner in making choices and in evaluating how well the chosen options match his or her current levels of motivation and capability ;

- Establishment of program plans and mutual agreements about the ongoing relationships between the learner and the program personnel;

- Regular reevaluations of decisions, reformulation of plans, and renegotiation of agreements based on mutual evaluations of progress, problems, and current learner perceptions of the "match." 
learning environment matches her or his motivation and capability. That is, the environment is a good match only if the learner perceives it as a good match.

Because learning is an ongoing, dynamic, and interactive process, a learning environment must continuously change to match changes in the learner. A student perceives the environment as personalized and responds by learning; the changes in him/her usually call for changes in the environment so that he will continue to perceive it as personalized. There must be an ongoing series of transactions and mutual changes on the part of the learner and the learning environment.

\section{Procedural Objectives}

Specifically, the teacher can be viewed as trying to accomplish a set of comprehensive procedural objectives to facilitate motivated learning. A primary objective is to establish and maintain an appropriate working relationship with students-for example, through creating a sense of trust and caring, open communication and providing support and direction as needed. This objective includes a focus on clarifying the purpose of learning activities and procedures (especially those designed to help correct specific problems) and why these procedures are expected to be effective. Each activity should build carefully on previous learning and present material in ways that focus attention on the most relevant features of what is to be learned-for example, each should use scaffolding, modeling, and cueing. To help minimize the negative impact of processes designed to provide continuous information about learning and performance, teachers need to clarify the nature and purpose of evaluative measures and apply them in ways that deemphasize feelings of failure. Then, there must be guidance and support for motivated practice-for instance, suggesting and providing opportunities for meaningful applications and clarifying ways to organize practice. Finally, teachers must provide opportunities for continued application and generalization-for example, concluding the process by addressing ways in which the learner can pursue additional, self-directed learning in the area or arrange for additional support and direction.

The focus in facilitating learners is not on one procedure at a time. Teachers usually have some overall theory, model, or concept that guides them toward certain procedures and away from others (Joyce $\&$ Weil, 1996). In general, procedures and content are tightly interwoven, with procedures seen as means to an end. In this connection, it is frequently suggested that learning is best facilitated when pro- 
cedures are perceived by learners as good ways to reach their goals. The emergence of advanced technology (e.g., computers, video) is providing many new opportunities to blend content and process together into personalized activities.

\section{Structure}

There appears to be a belief among some teachers that a tight and controlling structure must prevail if students are to learn (Joyce \& Weil, 1996). This view is caricatured when teachers caution each other: "Don't smile until Christmas!" Good structure allows for active interactions between students and their environment, and these interactions are meant to lead to a relatively stable, positive, ongoing working relationship. How positive the relationship is depends on how learners perceive the communication, support, direction, and limit setting. Obviously, if these matters are perceived negatively, what may evolve in place of a positive working relationship is avoidance behavior.

Some students-especially those who are very dependent, uninterested, or who misbehave-need a great deal of support and direction initially (Reid \& Maag, 1998). However, it is essential to get beyond this point as soon as possible.

As long as a student does not value the classroom, the teacher, and the activities, then the teacher is likely to believe that the student requires a great deal of direction. We stress that the less the student is motivated, the more it is necessary to teach and control behavior, and the less successful the whole enterprise of schooling appears to be. Conversely, the more the student is motivated, the less it is necessary to teach and control, and the more likely the student will learn.

To facilitate a positive perception, it is important to allow students to take as much responsibility as they can for identifying the types and degree of support, direction, and limits they require. In providing communication, it is important not only to keep students informed but also to interact in ways that consistently convey a sense of appropriate and genuine warmth, interest, concern, and respect. The intent is to help students know their own minds, make their own decisions, and at the same time feel that others like and care about them (Oyler, 1996).

To achieve these objectives, a wide range of alternatives must be available for support and direction so students can take as much responsibility as they are ready for. Some students request a great amount of direction; others prefer to work autonomously. Some like lots of help on certain tasks but want to be left alone at other times.

When a continuum of structure is made available and students are 
able to indicate their preferences, the total environment appears less confining. Although we see this as positive, it does tend to make many observers think they are seeing an open classroom or open structure, as these terms are widely understood (Smith, 1997). This is not necessarily the case. A better description might be that the intent is to make small classes within large ones. The main point of personalizing structure is to provide a good deal of support and direction for students when they need it and to avoid creating a classroom climate that is experienced by students as tight and controlling. Such an approach is a great aid in establishing positive working relationships.

\section{Options and Learner Decision Making}

Clearly, motivation is a primary consideration in facilitating the learning of such students. The place to start generally involves expanding the range of options related to content, processes, outcomes, and support so that these youngsters perceive classroom activity as a good fit with what they value and believe than can do.

Every teacher knows a classroom program has to have variety (Davis, 1997). There are important differences among students as to the topics and procedures that currently interest or bore them. For students with learning problems, more variety seems necessary than for those without learning problems.

Moreover, among those with learning problems are a greater proportion of individuals with avoidance or low motivation for learning at school. For these individuals, few currently available options may be appealing. An old joke has an exasperated teacher saying to a student: "I know you like lunch-time best, but there must be something else you'd like to do at school."

How much greater the range of options needs to be depends primarily on how strong avoidance tendencies are. In general, however, the initial strategies for working with such students involve further expansion of the range of options for learning, primarily emphasizing areas in which the student has made personal and active decisions, and accommodation of a wider range of behavior than is usually tolerated.

From a motivational perspective, one of the basic instructional concerns is the way in which students are involved in making decisions about options. Critically, decision-making processes can lead to perceptions of coercion and control or to perceptions of real choice (being in control of one's destiny and self-determining). Such differences in perception can affect whether a student is mobilized to pursue or avoid planned learning activities or outcomes (Deci \& Ryan, 1985). 
People who have the opportunity to make decisions among valued and feasible options tend to be committed to follow through. In contrast, people who are not involved in decisions often have little commitment to what is decided. If individuals disagree with a decision that aff ects them, they may also react with hostility.

Thus, essential to programs focusing on motivation are decisionmaking processes that affect perceptions of choice, value, and probable outcome. Optimally, we hope to maximize perceptions of having a choice from among personally worthwhile options and attainable outcomes. At the very least, it is necessary to minimize perceptions of having no choice, little value, and probable failure.

Yes, but ... . The idea of motivated learning and practice is not without its critics. One such criticism might be, "Your points about motivation sound good. I don't doubt that students enjoy such an approach; it probably even increases attendance. But (long pause) that's not the way it really is in the world. People need to work even when it isn't fun, and most of the time work isn't fun. Also, if people want to be good at something, they need to practice it day in and day out, and that is not fun! In the end, won't all this emphasis on motivation spoil people so that they won't want to work unless it is personally relevant and interesting?"

Learning and practice activities may be enjoyable. But even if they are not, they can be viewed as worthwhile and experienced as satisfying. We recognize that there are many things people have to do in their lives that will not be viewed and experienced in a positive way. How we all learn to put up with such circumstances is an interesting question, but one for which psychologists have yet to find a satisfactory answer. It is doubtful, however, that people have to experience learning basic knowledge and skills as drudgery in order to learn to tolerate boring situations!

In response to critics of motivated practice, those professionals who work with learning problems stress the reality that many students do not master what they have been learning because they do not pursue the necessary practice activities. Thus, at least for individuals experiencing learning problems, it seems essential to facilitate motivated practice.

One of the most powerful factors keeping a person on a task is the expectation of feeling some sense of satisfaction when the task is completed. For example, task persistence results from the expectation that one will feel smart or competent while performing the task-or at least will feel that way after the skill is mastered. This seems to 
characterize youngsters' interactions with video games and their various hobbies.

Beyond having potential for preventing and correcting a full range of learning problems, the personalized, sequential, and hierarchical approach outlined here is seen as having promise for identifying different types of learning problems and detecting errors in diagnosis. For example, when only personalization based on capability and motivation is needed to correct a learning problem, it seems reasonable to suggest that the individual does not have a learning disability. At the same time, when a highly mobilized individual still has extreme difficulty in learning, the hypothesis that the person has a disability seems more plausible. In our work, personalization is seen as a necessary step in facilitating valid identification of different types of learning problems.

\section{Step 2: Remediation}

Intervention can be costly-financially and in terms of potential negative consequences. Therefore, when professionals attempt to ameliorate problems, standards for good practice call on them to prescribe as much as is needed but no more than is necessary. The ability to provide what is needed, of course, depends on the availability and accessibility of an appropriate array of interventions. However, even if one has the good fortune to be able to prescribe from such an array, good practice requires using an intervention only when it is necessary and the benefits significantly outweigh the costs.

The desire to meet needs in ways that ensure the benefits outweigh costs (financial and otherwise) makes the concept of least intervention needed a fundamental intervention concern. This concept (and the related notion of placement in the least restrictive environment) find support in "the principle of normalization," which is associated with mainstreaming and deinstitutionalization. It is reflected in laws that protect individuals from removal from the "mainstream" without good cause and due process. Such legislation and associated regulations underscore concern that disruptive and restrictive interventions can produce negative effects, such as poor self-concept and social alienation. In turn, these effects may narrow immediate and future options and choices, thereby minimizing life opportunities.

As an intervention guideline, the concept of least intervention needed stresses that one must first and foremost strive to do what is needed, but in doing so, one must not interfere with an individual's opportunity for a normal range of experiences more than is absolutely necessary. Thus, even when a student has been diagnosed as in 
need of special education, placement in a special education class is inappropriate if the youngster can be worked with effectively in a regular classroom. At the same time, it should be evident that regular classroom placement is no guarantee of eff ectiveness.

From the foregoing perspective, concerns arise about research applications that encourage an overemphasis on narrowly focused assessment and remedial approaches in efforts to correct the wide range of learning problems found in public schools. For example, applied ideas for assessing and fostering development of language and cognitive abilities (e.g., phonological, executive function, writing, and mathematics skills) are appropriate and invaluable (Jordan \& Goldsmith-Phillips, 1994; Lyon \& Moats, 1997; Stahl, 1998). However, an overemphasis on remedying these areas of development could have the same unfortunate consequences as the historic overemphasis on remedying problems related to visual-spatial abilities. That is, when specific areas for remediation are overstressed, other areas tend to be deemphasized, resulting in a narrowing of curriculum and a fragmentation of instruction (Shannon \& Crawford, 1997).

Remediation is an extension of general eff orts to facilitate learning. Thus, before a remedial focus is introduced, the best available nonremedial instruction should be tried. As discussed, this means trying procedures to improve the match between the program and a learner's motivation and capability. A significant number of learning problems may be corrected and others prevented through optimal, nonremedial instruction. There does come a time, however, when remediation is necessary for some individuals. In the following section, we sketch criteria for deciding who needs remediation, outline its general features, and highlight the focus and form of remedial methods.

\section{When Is it Needed?}

Stated simply, an individual needs remediation when the best nonremedial procedures are found to be ineffective. As we have suggested, remediation is used for motivation problems and for those who have difficulty learning or retaining what they have learned.

Because remediation in all areas is usually unnecessary, as much learning as possible will probably continue to be facilitated with nonremedial approaches. Besides facilitating learning, such procedures provide an essential foundation and context for any remedial strategy, especially if they are valued by the learner.

\section{What Makes Remedial Instruction Different?}

Techniques and materials designated as remedial often appear to 
be very different from those used in regular teaching. However, the diff erences often are not as great as appearance suggests. So me remedial practices are simply adaptations of regular procedures. This is even the case with some packaged programs and materials especially developed for problem populations. A great many regular and remedial procedures draw on the same instructional models and basic principles (Gagné, 1985; Joyce \& Weil, 1996). Thus, the question is frequently asked: "What's so special about special education?" The answer to this question involves understanding the following factors that diff erentiate remedial from regular teaching.

Sequence of application and resource costs. Remedial practices are pursued after the best available nonremedial practices have been found inadequate. Due to the types of factors described below, remediation is more costly than regular teaching (allocations of time, personnel, materials, space, and so forth).

Teacher competence and time. Probably the most important feature differentiating remedial from regular practices is the need for a competent teacher who has time to provide one-to-one instruction. While special training does not necessarily guarantee such competence, remediation usually is done by teachers who have special training. Establishing an appropriate match for learners with problems is difficult. Indeed, a great deal of this process remains a matter of trial and appraisal. Thus, there must be additional time to develop an understanding of the learner (strengths, weaknesses, limitations, likes, dislikes). There must also be access to and control over a wide range of learning options.

Outcomes and content. Along with basic skills and knowledge, special education often adds other content and outcome objectives. These are aimed at overcoming missing prerequisites, faulty learning mechanisms, or interfering behaviors and attitudes.

Processes. Remediation usually stresses an extreme application of instructional principles. Such applications may include reductions in levels of abstraction, intensification of the way stimuli are presented and acted upon, and increases in the amount and consistency of direction and support-including added reliance on other resources. Of course, special settings (outside regular classrooms) are not the only places such processes can be carried out.

Psychological impact. The features of remediation are highly visible to students, teachers, and others. Chances are such features are seen as "different" and stigmatizing. Thus, the psychological impact of remediation can have a negative component. The sensitive 
nature of remediation is another reason it should be implemented only when necessary and in ways that result in the learner's perceiving remediation as a special and positive opportunity for teaming.

Special educators also have the responsibility to clarify whether general educators share the same basic concerns. Special educators are asked to take on an additional concern. Their responsibility is to clarify which general answers to educational matters are adequate for everyone and how the answers should be modified to account for specific subgroups of learners. Until much more is known about how to meet the needs of those who are not well served by regular classroom programs, a role for remedial teaching and special education will certainly remain.

Remediation, however, is not synonymous with either special education or special placements. Once one escapes from the debate over where a youngster should be taught, the concern shifts to fundamental factors that must be considered in meeting students' learning, behavioral, and emotional needs and doing so with the least intervention. Is there a full array of programs and services designed to address factors interfering with learning and teaching (e.g., such as those outlined in Figure 2)? Is there an appropriate curriculum (that includes a focus on areas of strength and weakness and encompasses prerequisites that may not have been learned, underlying factors that may be interfering with learning, and enrichment opportunities)? Do the staff have the ability to personalize instruction/structure teaching in ways that account for the range of individual differences and disabilities in the classroom (accounting for differences in both motivation and capability and implementing special practices when necessary)? Does the student-staff ratio ensure the necessary time required for personalizing instruction, implementing remediation, and providing enrichment?

\section{Levels of Remedial Focus}

As noted above, specialized psychoeducational procedures to facilitate learning can be applied at any of three levels (again see Figure $1)$.

Age-appropriate life tasks. Current life tasks involve a variety of basic knowledge, skills, and interests as part of day-by-day living at school, home, work, and in the neighborhood. These include reading, writing, interpersonal and intrapersonal problem solving, and so forth. At this level, remediation essentially involves reteaching, but not with the same approach that has just failed. Alternative ways 


\section{Intervention} Continuum

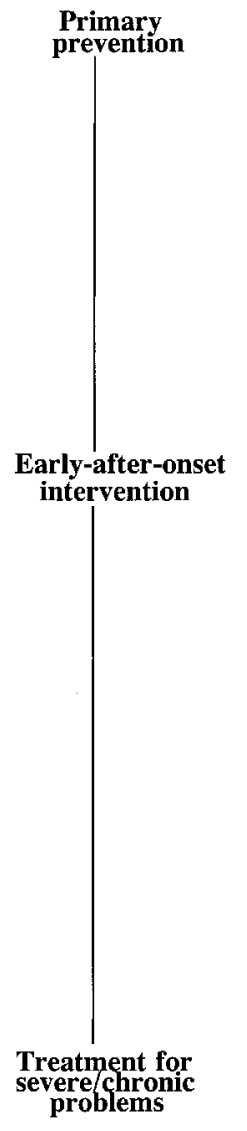

Examples of Focus and Types of Intervention

(Programs and services aimed at system changes and individual needs)

1. Public health protection, promotion, and maintenance to foster opportunities, positive development, and wellness

- economic enfiancement of those living in poverty (e.g., work/welfare programs; literacy programs; ESL classes)

- safety (e.g., instruction, regulations, lead abatement programs)

- physical and mental health (incl. healthy start initiatives, immunizations, dental care, substance abuse prevention, violence prevention, health/mental health education, sex education and family planning, recreation, social services to access basic living resources, and so forth)

2. Support and assistance to enhance health and psychosocial development for preschoolers and during early schooling

- systems' enhancement through capacity building and cross-disciplinary collegial teaming and assistance (including mentoring)

- education and social support for parents and surrogates

- quality day care/quality early education

- personalized instruction (especially in the primary grades)

- preparation and support for school and life transitions (incl. articulation programs and interventions to welcome, orient, and provide social supports for students and their families transitioning into school and community life)

- enhanced curricular and extra-curricular enrichment and recreation programs

- increased opportunities for young people to assume positive roles

- appropriate screening and amelioration of physical and mental health and

psychosocial problems

- support and guidance to ameliorate school adjustment problems

- additional support to address specific learning problems

- enhanced home involvement in problem solving

- comprehensive and accessible psychosocial and physical and mental health programs (including a focus on community and home violence and other problems identified through community needs assessment)

3. Improvement and augmentation of ongoing regular support

- enhance systems via school-wide approaches and school-community partnerships to build capacity and enhance cross-disciplinary collegial teaming and assistance

- teaching "basics" of support and remediation to regular teachers (including use of available resource personnel, peer and volunteer support)

- resource support for parents-in-need (including assistance in finding work, legal aid, ESL and citizenship classes, and so forth)

- comprehensive and accessible psychosocial and physical and mental health interventions (including health and physical education, recreation, violence reduction programs, and so forth)

- Academic guidance and assistance

- Emergency and crisis prevention and response mechanisms

4. Other interventions prior to referral for intensive, ongoing treatments

- enhance systems via school-wide approaches and school-community partnerships to build capacity and enhance cross-disciplinary collegial teaming and assistance

- short-term specialized interventions (including resource teacher instruction and family mobilization; programs for suicide prevention, pregnant minors, substance abusers, gang members, and other potential dropouts)

5. Intensive treatments

- referral, triage, placement guidance and assistance, management of care, and resource coordination

- family preservation programs and services

- special education, rehabilitation, and alternative placements

- dropout recovery and follow-up support

- services for severe-chronic psychosocial/mental/physical health problems

- systems of care

Adapted from: H. S. Adelman, \& L. Taylor (1993). Learning problems and learning disabilities: Moving forward. Pacific Grove, CA: Brooks/Cole.

FIGURE 2 From primary prevention to treatment of serious problems: a continuum of community-school programs.

must be used when the student has had difficulty learning. This is accomplished by further modifying activities in ways likely to improve the match with the learner's current levels of motivation and capability. Teachers can use a range of environmental factors to influence the match, as well as techniques that enhance motivation, sensory intake, processing and decision making, and output. 
Prerequisites. At this level, the focus is on identifying and teaching missing prerequisites. Procedures are the same as those used in facilitating learning related to current life tasks.

Interfering factors. At this level, we must face the possibility of faulty learning mechanisms. A variety of underlying problems has been suggested as interfering with learning. Remedial approaches are designed to overcome such deficiencies by directly correcting the problems or indirectly compensating for them.

It is evident that remediation, especially in the classroom, is often delayed because so many individuals with learning problems also manifest behavior problems. Such individuals are frequently described not only as learning disabled but also as hyperactive, distractable, impulsive, emotionally and behaviorally disordered, and so forth. Their behavior patterns are seen as interfering with efforts to remedy their learning problems, and for many students, such interfering behaviors have to be eliminated or minimized in order to pursue remediation. The focus in such cases is on any actions of an individual that compete with the intended focus of remediation. Besides trying to reduce the frequency of deviant and disruptive actions directly, programs have been designed to alter such behavior by improving impulse control, selective attention, sustained attention and follow-through, perseverance, frustration tolerance, and social awareness and skills.

In sum, what makes remedial strategies appear different is their rationale, the extreme degree and consistency with which they must be applied, and their application on levels of functioning other than current life tasks. What may make any remedial procedure work is the fact that it is diff erent from those a student has already tried and found ineffective. Special procedures have the benefit of being novel and thus having motivational and attention-inducing value.

As a general stance regarding remedial activity, we concur that learning problems and learning disabilities "cannot be corrected or 'cured' by a special teaching method or training technique. It is imperative that teachers have a wide range of instructional materials and techniques at their disposal and that they are imaginative and flexible enough to adapt these to the specific needs of their pupils" (Koppitz, 1973, p. 137). We would add, however, that eff ective flexibility and imaginativeness in facilitating learning stem from a sound understanding of what is involved in personalizing regular and remedial instruction. 


\section{A SOCIETAL APPROACH TO INTERVENTION}

Beyond the classroom, an even broader perspective is evolving regarding research and practice for problems related to learning and behavior. Policymakers increasingly are recognizing the importance of multifaceted approaches that account for social, economic, political, and cultural factors. The potential array of prevention and treatment programs is extensive and promising. The range can be appreciated by grouping them on a continuum from prevention through treatment of chronic problems (again, see Figure 2). Activities along this continuum encompass primary prevention to promote and maintain safety and physical and mental health, preschool programs, early school adjustment programs, improvement of ongoing regular support; augmentation of regular support, specialized staff development and interventions prior to referral for special help, and system change and intensive treatments. Examples of relevant interventions are cited in Figure 2.

Unfortunately, implementation of the full continuum of programs outlined in Figure 2 does not occur in most communities. Moreover, what programs there are tend to be off ered in a fragmented manner.

Policymakers see a relationship between limited intervention efficacy and the widespread tendency for complementary programs to operate in isolation. For instance, physical and mental health programs generally are not coordinated with educational programs, or a youngster identified and treated in early education programs who still requires special support may or may not receive systematic help in the primary grades. Failure to coordinate and follow through, of course, can be counterproductive (e.g., undermining immediate benefits and working against efforts to reduce subsequent demand for costly treatment programs). Limited efficacy seems inevitable as long as interventions are carried out in a piecemeal fashion. Thus, there is increasing interest in moving beyond piecemeal strategies to provide a comprehensive, integrated, and coordinated programmatic thrust (e.g., Adelman, 1993, 1996; Adelman \& Taylor, 1997; Greenwald, Hedges, \& Laine, 1996; Hodgkinson, 1989; Kagan, 1990; Sailor \& Skrtic, 1996).

The range of programs cited in Figure 2 can be seen as integrally related, and it seems likely that the impact of each could be exponentially increased through integration and coordination. Indeed, a major breakthrough in the battle against learning and behavior problems may result only when the full range of programs are implemented in a comprehensive and integrated fashion. 


\section{CONCLUDING COMMENTS}

Researchers primarily concerned with improving intervention for those with learning problems must at the very least broaden their view of teaching. Optimally, they need to expand their view beyond teaching. Whatever their view of intervention, it is essential that they focus on motivation as a primary intervention concern. Beyond teaching, it is important to think in terms of a societal approach encompassing a comprehensive continuum of multifaceted, integrated programs and services. There is a considerable agenda of research that warrants attention related to these ideas.

As the world around us is changing at an exponential rate, so must the way we approach learning difficulties. Everyday, our society is called upon to do something about the many individuals who have trouble learning academic skills. In responding to this call, we must be prepared to go beyond the narrow perspective of specific assessment practices or direct instruction of observable skills. What is needed is a broad understanding of what causes learning problems (including learning disabilities) and what society in general and schools in particular need to do to address such problems.

\section{REFERENCES}

Adelman, H. S. (1971). The not so specific learning disability population. Exceptional Children, 8, 114-120.

Adelman, H. S., \& Taylor, L. (1977). Two steps toward improving learning for students with (and without) "learning problems." Journal of Learning Disabilities, 10, 455461.

Adelman, H. S., \& Taylor, L. (1990). Intrinsic motivation and school misbehavior. Journal of Learning Disabilities, 23, 541-543.

Adelman, H. S., \& Taylor, L. (1993). Learning problems and learning disabilities: Moving forward. Pacific Grove, CA: Brooks/Cole.

Adelman, H. S., \& Taylor, L. (1994). On understanding intervention in psychology and education. Westport, CT: Prager.

Adelman, H. S., \& Taylor, L. (1997). Addressing barriers to learning: Beyond schoollinked services and full service schools. A merican Journal of Orthopsychiatry, 67, 408-421.

Bandura, A. (1978). The self system in reciprocal determinism. American Psychologist, $33,344-358$.

Brehm, S. S., \& Brehm, J. W. (1981). Psychological reactance: A theory of freedom and control. New York: Academic Press.

Bruner, J. S. (1966). Toward a theory of instruction. Cambridge, MA : Belknap.

Davis, S. C. (1997). Reading assignments that meet literacy needs: Alternatives to the textbook. Reading \& Writing Quarterly, 13, 303-309.

Deci, E. L., \& Chandler, C. L. (1986). The importance of motivation for the future of the LD field. Journal of Learning Disabilities, 19, 587-594. 
Deci, E. L., \& Ryan, R. M. (1985). Intrinsic motivation and self determination in human behavior. New York: Plenum Press.

Dev, P. C. (1997). Intrinsic motivation and academic achievement: What does their relationship imply for the classroom teacher? Remedial and Special Education, 18, $12-19$.

Fuchs, D., Fuchs, L. S., Mathes, P. G., \& Simmons, D. C. (1997). Peer-assisted learning strategies: Making classrooms more responsive to diversity. A merican Educational Research Journal, 34, 174-206.

Gagné, R. M. (1985). The conditions of learning and theory of instruction (4th ed.). Fort Worth, TX: Holt, Rinehart and Winston.

Greenwald, R., Hedges, L. V., \& Laine, R. D. (1996). The eff ect of school resources on student achievement. Review of Educational Research, 66, 361-396.

Guthrie, J. T., \& Wigfield, A. (Eds.). (1997). Reading engagement: Motivating readers through integrated instructions. Newark, DE: International Reading Association.

Hodgkinson, H. L. (1989). The same client: The demographics of education and service delivery systems. Washington, DC: Institute for Educational Leadership, Inc./Center for Demographic Policy.

Hunt, J. McV. (1961). Intelligence and experience. New York: Ronald Press.

Johnson, L. J., \& Pugach, M. C. (1991). Peer collaboration: Accommodating students with mild learning and behavior problems. Exception Children, 57, 454-461.

Jordan, N. C., \& Goldsmith-Phillips, J. (Eds.). (1994). Learning disabilities: New directions for assessment and intervention. Boston: Allyn \& Bacon.

Joyce, B., \& Weil, M. (1996). Models of teaching. 5th ed. Boston: Allyn \& Bacon.

Kagan, S. L. (1990). Excellence in early childhood education: Defining characteristics and next-decade strategies. Washington, DC: Office of Educational Research and Improvement, U.S. Department of Education.

Koppitz, E. (1973). Special class pupils with learning disabilities: A five year follow-up study. Academic Therapy, 13, 133-140.

Lyon, G. R., \& Moats, L. C. (1997). Critical conceptual and methodological considerations in reading intervention research. Journal of Learning Disabilities, 30, 578588.

Marr, M. B. (1997). Cooperative learning: A brief review. Reading \& Writing Quarterly, $13,7-20$.

Morrow, L. M., \& Sharkey, E. A. (1993). Motivating independent reading and writing in the primary grades through social cooperative literacy expectations. Reading Teacher, 47, 162-165.

Oyler, C. (1996) Making room for students: Sharing teacher authority in Room 104. New York: Teachers College Record.

Piaget, J. (1952). The origins of intelligence in children. New York: International Universities Press.

Reid, R., \& Maag, J. W. (1998). Functional assessment: A method for developing classroom-based accommodations and interventions for children with ADHD. Reading \& Writing Quarterly, 14, 9-42.

Sailor, W., \& Skrtic, T. M. (1996). School/community partnerships and education reform: Introduction to the topical issue. Remedial and Special Education, 17, 267$270,283$.

Shannon, P., \& Crawford, P. (1997). Manufacturing descent: Basal readers and the creation of reading failures. Reading \& Writing Quarterly, 13, 227-245.

Slavin, R. E. (1994). Cooperative learning: Theory, research, and practice. 2nd ed. Boston: Allyn \& Bacon. 
Slavin, R. E., Karweit, N. L., \& Madden, N. A. (Eds.). (1989). Effective programs for students at risk. Boston: Allyn \& Bacon.

Smith, L. H. (1997). "Open education" revisited: Promise and problems in American educational reform (1967-1976). Teachers College Record, 99, 371-415.

Stahl, S. A. (1998). Teaching children with reading problems to decode: Phonics and "not-phonics" instruction. Reading \& Writing Quarterly, 14, 165-188.

Stipek, D. J. (1998). Motivation to learn: From theory to practice. 3rd ed. Boston: Allyn $\&$ Bacon.

Sweet, A. P., \& Guthrie, J. T. (1996). How children's motivations relate to literacy development and instruction. Reading Teacher, 49, 660-662.

Vygotsky, L. S., Vygotsky, S., \& John-Steiner, V. (Ed.). (1980). Minds in society: The development of higher psychological processes. Cambridge, MA : Harvard University Press.

Weiner, B. (1985). Human motivation. New York: Springer Verlag. 